\title{
COLONIAL HETEROTROPICS AND GLOBAL HERITAGE AESTHETICS IN ROUNDHAY'S TROPICAL WORLD, LEEDS
}

\author{
Rodanthi Tzanelli
}

Can we move things out of their context under the imperative to educate the world in profitable ways? In what follows, the present book's key question - how museums can enhance their 'art of relevance' in post-Enlightenment contexts overlaid by the necessity to attract visitors in consumerist environments - acquires new poignant extensions. I explore the intentional acclimatisation of atmospheric, floral and faunal forms originating in remote, tropical systems in Leeds, North Yorkshire, UK. I refer to the more recent commercial operation of Tropical World (heretofore TW) as a living establishment of physical environments belonging to other parts of the world. TW is based in Coronation House (built 1939), a building named after George V's year of coronation (1911), which was refurbished in 1983 as Tropical World. Financially relaunched as The Arnold and Marjorie Ziff Tropical World in 2008, it includes a group of temperaturecontrolled greenhouses. Since 2015, these greenhouses have been operating in sustainable, energy-saving ways. TW is also one of the UK's popular garden tourist attractions and home to the largest collection of tropical plants outside Kew Gardens in London.

\section{The experiment}

The 'human right' to enjoy the outdoors and collect impressions continues to guide the contemporary enterprise of knowing about nature as an objectified 'thing.' However, we live in a 'posthuman era,' in which prioritising human interests goes against the project of non-hierarchical coexistence of different species in an ecology embracing animals, plants and humans. 'Posthumanism' calls for critical re-evaluations of 'the basic unit of common reference for our species, our polity and our relationship to the other inhabitants of this planet' (Braidotti, 2013 , p. 2): the human subject, earth's main ruler and destructive force. Still, even 
where humans enter local lifeworlds as strangers to enjoy their environments as objects (Fletcher \& Neves, 2012) as is very much the case with Kew Gardens, nature produces spheres of experience, challenging their objectification of surroundings and occasionally making them reconsider their thoughtlessness (MacCannell, 2011). The power of humans to beautify the natural world is stronger now that post-industrial development threatens it with annihilation. In the form of banal activities (a walk in a natural park or a museum), the natural world continues to assert itself as one of late modernity's principal actors. This paradox recurs in all instances of human progress written from a privileged Western European standpoint: the hurt or eliminated populations begin to haunt such scripts, even though they may not be physically present in this world anymore (Herzfeld, 2002). This issue of who is qualified to be recognised as the rightful custodian in Leeds exceeds the limits of the present study, and merits unpacking on its own. For the purposes of this chapter, I will be talking about 'atmospheres' to refer to such hauntings, which incorporate both physical manifestations (TW's preserved climates, plants and animals), and aethereal experiences (the inducement of cognitive and emotional work in visitors through TW's staging of environments).

The atmospheres visitors encounter in the TW are physically portable, materially malleable (they can be staged) and, though experientially nuanced (humans feel them in varied ways), in terms of messages, easily stabilised (someone fixes their aesthetic and moral content). With this in mind I stress that TW is not just a tourist attraction - this popular presentation of its function is justified only by its geographical proximity to a leisure complex in one of Leeds' more affluent areas. Instead, we should see it as an experiment in physically relocating alien forms of life (flora, fauna and the atmospheric environments necessary for these forms to survive) in what used to be both the cradle of the Industrial Revolution (Yorkshire) and part of the British Empire. Such experiments were constitutive of the colonial machine's attempt to classify, catalogue and symbolically appropriate subjugated people's inheritances and heritages - an experiment with various extensions in the contemporary tourist business (Hollinshead, 2009). What contemporary visitors experience from visitations to the TW and the adjacent Roundhay Park is not just nature but the coexistence of different forms of heritage, some of which are human and some environmental, turned into commoditised objects in the tradition of dark tourism. Involving the commercialisation of sites of both environmental and man-made calamities, such as war events, slavery, terrorist tragedies and climate-induced disasters such as flooding, 'dark tourism' often centres on specific places enclosing human memory (Dann \& Seaton, 2001). The portability of 'tropical' environmental imaginaries hosted in the TW revises such set definitions, allowing TW's custodians to move other cultural heritages to different temporal, geographical and digital domains.

TW's mission to educate about foreign climates and species is produced in a variety of virtual and textual forms, including brochures and two different websites. However, there are still problems with its programmatic statement: on the 
one hand, displays of plants, animals and recreated natural atmospheres suggest that the mission is to protect life, not dead objects. This challenges traditional understandings of the museum as a space to display things that do not interact with visitors, and have identities assigned to them by humans. In a posthuman context, animals and plants do have agency, in that they communicate their inheritances with some immediacy and intimacy that we associate with human narratives, through their contextual presence. However, TW's experts seem to place its technologically controlled reproduction of alien environments in a new context of emergency, which overrides that of (post)colonial violence. This is known as the Anthropocene, the era of human domination over the earth's life course. Thus, currently, TW's experiment focusses on teaching through science that all humans are at risk of extinction because of their uncontrolled activities of pollution or thoughtless and unsustainable consumption (Beck, 2009). This posits the abstract 'Human' as the new self-destructive coloniser, who must be alerted to the consequences their activities have on ecological diversity as global natural heritage.

\section{The proposition}

Admittedly, this alleged global heritage bears the potential to produce new hybrid worlds of cultural synergy, for future global, rather than British, generations (Aravamudan, 1999; Delanty, 2009). Such synergies between local and international museum experts and local governmental authorities from the Parks and Countryside division could remake the script on which TW stages its exhibits in just ways. But this is my proposition and not what really happens. Framed as a critical museological intervention, my proposition points to gaps and potentialities in TW's design. Through an analysis of the ways TW's living collections are currently staged, I highlight problems that stand in the way of such fusions of horizons. Many speak today about nature's suppressed voice or rights (Badmington, 2003), so museological narratives of custodianship must address 'natural inheritance' in a revised posthuman-cosmopolitan fashion.

It helps remembering that colonial destruction of native cultures and instillations of master narratives of Western civilisation in colonised regions outside Europe went hand in hand with the modification of their physical environments. Blaming the natives for environmental degradation induced by colonists was often followed by the transportation of species and plants to the colonial metropolis as objects of science, curiosity or trade (MacKenzie, 1997, p. 45). The 1993 United Nations Convention on Biodiversity challenged the assumption that the earth's biological and genetic resources are part of the 'global commons,' by giving property rights over these resources to the nation-state. Colonists and scientists often used the principle of a commons 'when, in reality, the expansion of European property laws to the colonies meant the appropriation of lands and resources commonly held and used by aboriginal communities' (Merson, 2000, p. 286). In contemporary posthuman contexts, relocations of tropical heritage postulate questions of biopiracy, because they are based on considerations of the 
environment as an object to be used, and thus lacking this kind of citizenship with which it is endowed by place. The Anthropocenic argument framing the British right to educate the world is, in fact, rooted in the ways all human and posthuman lifeworlds have been colonised by specific ways of doing things. One of them involves tourism as a consumerist journey rather than a pilgrimage. As much as TW's educational project would merit from a more explicit audio-visual or embodied-performative projection of its contents' real biographies and journeys through time and space, its portable tourist-like imaginaries of adventure remove any notion of agency from its gazed 'objects,' placing it in the hands of capitalist networks (Moore, 2016; Salazar \& Graburn, 2016).

This erasure is embedded in juxtapositions of two different types of gazing, currently coexisting in the staging of TW's collections: that of the tourist as an objective expert and the pilgrim as a subjective/existential, caring savant. It must be stressed that subjective patterns of perception of the TW's exhibits and the objective properties of perceived objects originate in different places and times they are, what is known as 'heterotopias.' Put simply, the social and cultural lives and environments of the living collections never or rarely meet without some form of forced engineering (Foucault, 1986). Consequently, this meeting and merging of other (heteroi) places (topoi) into a single 'tropical' narrative in Leeds can participate in processes of diversity elimination. In addition to recognising biodiversity, this encompasses the recognition of the diversity of the cultures (and their geographic coordinates) from which these climates were transported. 'Tropical' signifies a unity that overrides the real diversity of all the places/ countries/cultures (topoi) from which TW's displayed plants and animals came.

We arrive at an ethical crossroads, with a twin aesthetic potential: what does it mean to have the TW as a tourist and schooling establishment in Britain with such a political background, barely acknowledged? Should we ignore this background so that we allow its current British custodians to educate visitors about 'global' environmental heritages? Given the frequent school excursions to TW, the establishment's 'globalised natural heritage' has acquired schooling potential for those who start their lives as earth's systemic-natural equilibrium may be approaching its end. I propose that TW's practices of display and global, digitised now, communication of exhibits, should address a moral conflict between different experiential perspectives in custodianship and display of alien tropical species to diverse audiences. To address this, I explore clashes between the establishment's pragmatic objectives (to attract visitors and educate them) and phenomenal-moral calls (acknowledging what it means to host alien climates and tropical species without recognising their journey to the erstwhile imperial metropolis, so as to transform them into educational-touristic objects). This brings to the fore questions of design and public access of TW's narratives, as well as strategies of marketing with respect for forms of cultural difference.

Without ignoring questions of colonial violence in such symbolic appropriations of inheritances, I follow TW's in-progress narrative and treat the establishment's predicament in posthuman ways. I argue that TW's experiment can do more than 
'educate' in science - the institution's current priority: it can enlarge planetary consciousness by adopting the very 'confessional' styles the imperial machine once imposed on indigenous populations. Such styles were used to blame environmental destruction on the natives, ignoring who started this process while simultaneously depriving them of the means to prevent it or the resources to achieve flourishing in a healthy physical and social environment. As explained later, the experiment's institutional manager, the Leeds City Council, already attempts to bring together some of the phenomenal and pragmatic aspects of these atmospheric backgrounds in ways approximating the praxeological rationale of museum studies (Shelton, 2013), but the attempts clash with commercial imperatives.

In the tradition of such praxeological museology, I borrow from the gaze of the expert to enact processes of 'deep seeing' (Azcárate, 2018, p. 12) of TW's collections. Such depth is enacted through reflecting on photographic diaries of the collections produced by myself, but also by my embodied and digital journeys (scrutinising TW's presentations online) to them in the style of pilgrimage. I visited the TW and its gardens twice, and produced a photographic diary of my visits, which allowed me to reflect on the experience at a later stage. My first visit was in the context of an international family reunion, which posited me as a family photographer; the second visit involved a more focussed tour associated with the gaze of the researcher, rather than the tourist. Thus, 'deep seeing' was produced in stages: first, through combinations of my experience of walking the TW in two different modes and roles that I discuss in this chapter, its re-evaluation through two digital tours at a later stage, and finally the educational statement provided by TW in its brochure. However, such a 'truth test' is not enough to validate the TW's project. In the last part of the chapter I perform a 'reality test,' in which I re-evaluate my own experience from a social perspective. This coerces me to set both my ways of apprehension and the official atmospheric stagings or representations of 'tropical collections' against the conditions under which they are constructed (Boltanski \& Thévenot, 2006, p. 62) - something actualised through a political now pilgrimage. The politics of such material and ideal mobilities thrive on a global hierarchy of value, which apportions rights and privileges to the subjects and objects that move (Cresswell, 2010). Thus, a political pilgrimage to the TW aims to counter cultures of thoughtlessness instilled in visitors by consumerist fascination and objective science. In the following section I provide a 'tour' to TW's key collections to initiate discussions on visitor experience. This is examined from the perspective of atmospheric staging in TW's various rooms and the building's aesthetic-structural design. The discussion of 'tacit,' multi-sensory visitor experience is followed by some observations on TW's digital tours, which, as exercises in mono-sensory apprehension (vision), do more than introduce viewers to the collections. In section three I examine connections of the leisure complex to which the TW is adjacent, to consumption regimes and touristic activities (Soper, 2007). I connect institutionalmuseological arguments to a critique of new capitalism, which promotes entrepreneurialism and individualist innovation as blueprints of social agency in urban areas, with consequences for TW's project. 


\section{Educational journeys, on and offline}

Coronation House is an imposing structure, whose incorporation of glass produces a secondary protective structure (sun can penetrate glass and assist in the preservation of life) (Figure 5.1).

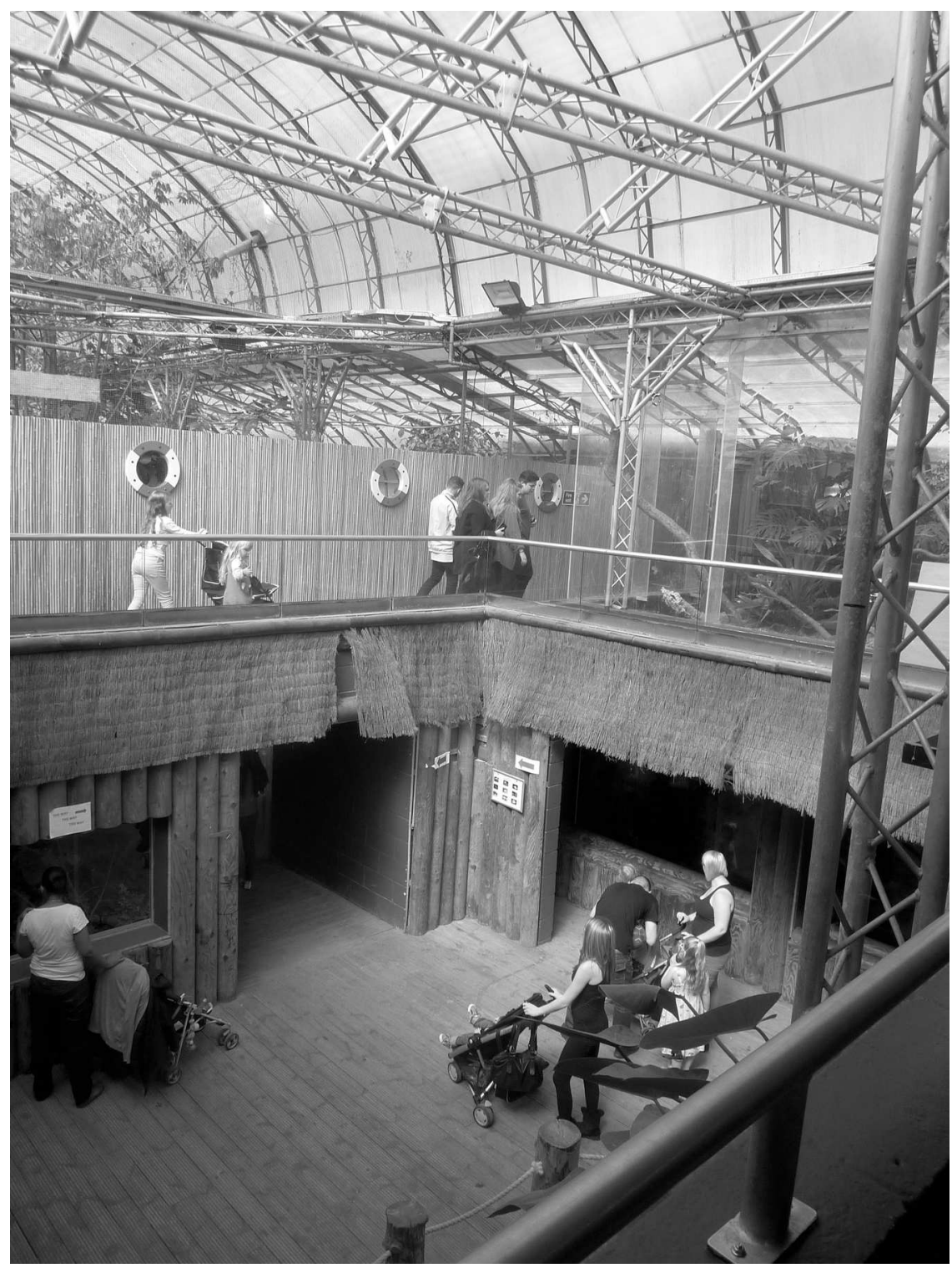

FIGURE 5.1 The main TW building includes a ground and an upper level that communicate through elevated walkways. 
Within it, we experience a contraction of space, which stands in opposition to the expansion of time, as all TW rooms open up millennia of natural evolution to visitors. The contraction of space is unavoidable: the building has a Butterfly House, a Desert House and a Jungle, in which birds, reptiles and other animals (including meerkats, a species facing extinction due to climate change) live free in enclosures. A nocturnal house hosts bats, whereas a recently refurbished 'Aztec Zone' has merged with an Amazon-themed area, in which one finds salamanders and piranhas. Passages to other rooms are mostly decorated with signposting and information on different species, in ways approximating the display of conventional museum collections (Figure 5.2).

The upper level hosts the atmospheric collections together with re-created environments for the species, whereas insects and some reptiles are stored in glass enclosures embedded in the walls of that level. The 'tropical' exhibits commence on ground level via the establishment's café, through which one reaches the area where reptiles are preserved in glass compartments on the walls. From this area, visitors reach the spaces in which recreated environments and flora and fauna are displayed. While walking on an elevated from the ground bridge, which splits into different directions, visitors can experience tropical environments at less than a metre's distance, as these are separated from them. The lower level, where butterflies and exotic fish in ponds are, is connected to an upper level, which is progressively elevated, with more plants, varieties of birds and animals. Enclosures on this level host meerkats and turtles. Through these areas, visitors are directed to another dark area, where they can see nocturnal animals, such as bats, in more glass enclosures. These areas are designed as tropical environments complete with their atmospheres, which are characterised by high levels of humidity. The experience of walking through these natural habitats is enhanced by their staging on natural soil and wood, rather than boards and concrete. This acts in unison with technology, which helps to produce appropriate micro-climates. There is a feeling of containment that, together with the omnipresence of excessive humidity, suggests to visitors that they entered a tropical world of adventure. The most appropriate term to describe this structural atmosphere is 'imaginarium': a copy (Latin root ima) of forms of life (Latin suffix ago) that have morphed into objects of speculation or amazement as finished images. This sort of engineering draws on the free faculty of imagination, enabling visitors to experience their own tailor-made journeys in delimited spaces. Comparable to tourist markers, such signposts expand the temporal dimensions of the journey/visit, feeding back to ad hoc visitor perceptions of the actual displays and the designed environments.

The visitors' apprehensions of the exhibits are supposed to enable an awareness of, and reflection on the power humans hold in the production of life and time (Caton, 2013). This is achieved pragmatically through immediate encounters with their staged conservation in TW's rooms: our earth's (and Leeds') master climate, which follows the non-linearity of the earth's climate system in episodic, abrupt and multi-equilibrium ways (Urry, 2005) through flooding and other disasters currently plaguing the region, is erased. Instead, the visitors' minds and bodies are 


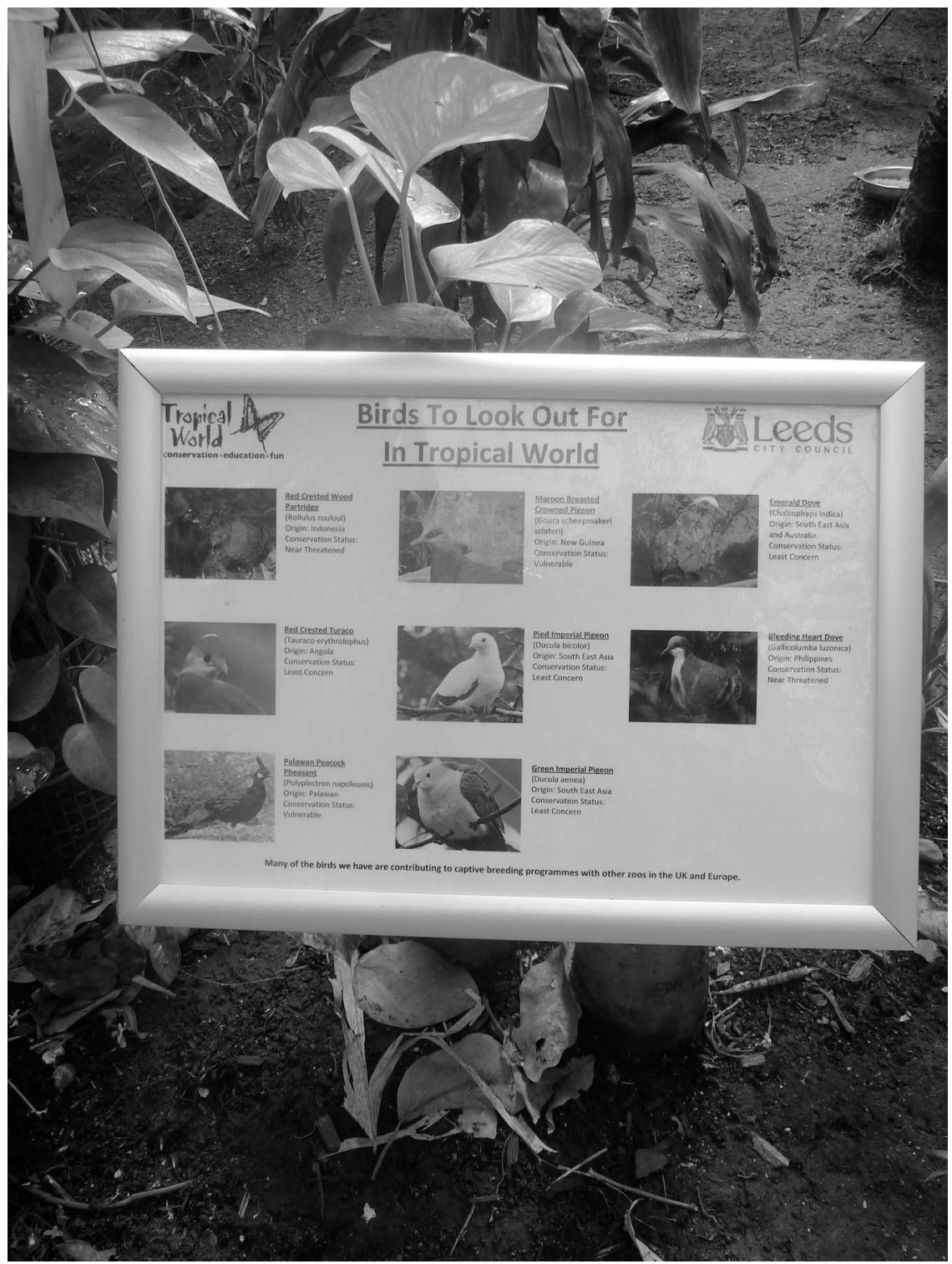

FIGURE 5.2 Each quarter of the walkways includes signposting that discusses the species of the room/area.

immersed in the natural audio-visual and ethereal atmosphere of the tropics from which plant and animal species came. In other words, a utopian equilibrium we do not really enjoy any more is restored in TW's rooms: silence is disrupted by the birds and the artificial ponds' surface is rippled by its underwater inhabitants. Because the environment is alive with creatures, it imparts the feeling of magic: 
the perception of movements and the actual movements of creatures merge with what the visitor's eye, ear and body learn about these alien worlds. This atmospheric staging recalls Benjamin's ([1935] 1969) discussion of the 'aura's' dual quality as a perceptual pattern (the visitor experiences and perceives of environments) and the perceived object's (animals, birds and plants) inherent property.

Despite its constructive dialogical modus vivendi, TW's use of science in the domestication of otherness calls for a critical re-evaluation of the place's institutional design, as consuming beautiful and valuable things without considering their mobility histories has been one of the pitfalls of Enlightenment and colonial rationalisation. Brockway (2002, p. 7) sees in the British botanic garden network in the period 1841-1941 the consolidation of plant transfers from the former colonies to the European core and scientific plant development in Western metropoles, 'which altered the patterns of world trade and increasing the plant energy, and human energy ... extracted from the tropical peripheries of the world system.' She proceeds to compare as famous botanical gardens as the Kew Gardens with the exploitative function of rubber plantations of Malaya, developed from seeds of wild Brazilian rubber, also noting how Latin American states, such as Brazil, Mexico, Colombia, Peru, Ecuador and Bolivia, 'each lost a native industry as a result of these transfers' of species from indigenous lands to the British colonial centre (Brockway, 2002, p. 451). Admittedly, currently, there is no display of such institutional reflexivity in TW's narratives, but the experiment is still fairly recent. The production of a reflexive script would expose what Sahr (2011, p. 111) discusses as the 'cutting out [of] a life form from the relational world' to which it naturally belongs. Sharing these lifeworld relationalities as part of a global temporal movement from colonialism to industrialisation that culminated in the age of capitalist eco-destruction, has been at the heart of other similar experimental projects, such as that of the Museum of Tomorrow (Museu do Amanhã) in Rio de Janeiro (Tzanelli, 2018b). Conceptualised as an open-ended narrative on climate change and the future of humanity through artistic artefacts and audio-visual displays to engage visitors in decision-making scenarios about collective futures, as well as aspiring to act as a global hub for natural science and ecological art, the Museum of Tomorrow is a step ahead from the less well-networked TW.

The imaginarium's containment of species in corners plunged in natural darkness turns the living collections into sites of intimacy, which are nevertheless intended for onlookers. 'Visual prying' in these areas affords learning about phenomena inaccessible to most humans, but the act of gazing produces tourist imaginaries, ways of conceptualising tropical worlds as tourist objects and concepts (Salazar, 2012; Salazar \& Graburn, 2016). Naturally dark enclosures coexist with illuminated areas on the upper level of the building, enabling the visitors' mobility and highlighting areas worthy of inspection. As a result, tropical life becomes designated as a precious form of darkness, standing now in opposition to colonial violence. This reframing of tropical life challenges traditional oppositions of darkness (the colonised subject) and light (lumen), as the Cartesian source of outer, Western scientific knowledge (Ingold, 2011, p. 256). Instead, the staging invites 
holistic engagement with tropical natures. The subjective conditions of this atmospheric experience involve the kinetic training of the visitor, who must learn to follow plants' and animals' routines in their natural environments, while not just looking at, but also breathing their natural atmospheres. The training turns an unconscious physiological activity (oxygen inhalation) into a metaphorical 'inhalation' of the perceptible: climate (Rauch, 2018, pp. 67-68).

As much as there is an effort to treat tropical species and atmospheres as subjects, their scientific objectification persists in print and digital narrations of the project. This is particularly prevalent in the educational pack addressed to young visitors. The pack's invitation to explore different exhibits will be followed by actual guided tours in very narrow spaces and corridors that remove disinterested play from the adventure. In other words, the invitation to young pupils to engage in exploring 'this and that' (Barthes, 1981, pp. 4-5) is overridden by uses of scientific language, to represent, rather than present reality (Danston \& Galison, 2007; Jasanoff et al., 1995; Latour, 1987). Alongside a revision of amnesiac presentations of the collections as 'things out of time' at the service of their current custodians, the project would benefit from introducing more embodied, performative ways of learning for its young visitors, which do not remove play from the act of learning. The absence of such embodied rituals conforms to treatments of climate and alien forms of life as objects of scientific fascination, in contradistinction with children's disinterested captivation by the natural world.

Although digital presentations of TW's contents to its prospective adult visitors are fully developed, there is space to re-evaluate representations of visitor profiles, as currently, images suggest that they are exclusively white and middle-class. Digital presentations of TW's contents appear in two different websites, one managed by the city council, and another independently published website (not funded by public bodies, including the Leeds City Council) by Red Door VR Limited, which produced digital tours to its exhibits. Unlike Red Door VR's tourist gaze (Urry \& Larsen, 2011), the official website's presentation of the exhibits places the digital gaze at an intimate proximity to tropical nature. Species close-ups framed with narratives of TW's re-created tropical spaces give the impression that we deal with de-mediated lifeworlds. The technique is that of a 'popular-cultural journey' (Gyimóthy et al., 2015), which is suitable for families. It is based on the logic of impression-collecting, which we associate with family photography (taken by family members), hence human belonging and leisurely eco-tourism (Haldrup \& Larsen, 2003, 2010; Larsen, 2005; Larsen et al., 2006).

Generally, embodied peripatetic visitors are more certain that they experience realities without mediations tarnished by centuries of First-World politics and industrial ecological deterioration. Contrariwise, digital visitors are confronted with the possibility that they are estranged from earth as a multispecies 'home' (Braidotti, 2013). In contradistinction to the official website's static images, Red Door VR presents a free online Tour of TW, which is worth comparing to TW's official website's ways of seeing. Red Door VR's tour employs a centric perspective that guides visitors through TW's rooms, including one (Australasia 
House), which 'has been used as a set for film and television, even for a pop group video!' (Tropical World, Virtual Tour, 2019). Red Door VR's centrism is actualised by placing the tour's gaze at the centre and then gyrating to capture digital surroundings, like seeing from a carousel. This panoramic presentation of space emplaces the visitor's gaze at the centre of the room (hence, the recreated tropical ecosystem), promoting an anthropocentric narrative haunted by a particular understanding of unattainable 'homecoming': pristine natural environments can only be staged, re-created in the era of Anthropocenic destruction, not physically felt/ experienced.

The digital conception of an irretrievable 'home,' which is under attack by forces beyond individual human control, transforms the cybergazer's cognitive and emotional journey into an end in itself: a pilgrimage of sorts into the unknown future. The feeling of loss is emblematic of what Bauman (1996) recognises in the postmodern tourist's endless search for belonging and Augé (2008) as the disorientating feeling induced by the non-places of contemporary capitalism, which can be anywhere and anything, as they are stripped of their original identity (Tzanelli, 2018a, p. 103). Where panorama theatre views often connect to the political staging of national memory and identity from an omniscient point of view (Taussig, 1997, pp. 79-80). The Red Door VR's panoramic gaze questions whether and how humans are part of a larger-than-them whole. The tour enables them to visually retrieve and apprehend a pristine master ecosystem before its incremental and ongoing destruction. There is ambivalence in this design, which is supposed to act as a mirror image of TW's room designs: the webpage in which Red Door VR's moving digital tours are organised hosts mundane tourist and consumption practices, explicitly promoting the system of local tourist services through various advertising vignettes of eateries, cafes, hotels and activities. In this respect, the idea of slow pilgrimage is annulled before it reaches its embodied, offline phase.

The heavy commercialisation of digital tours suggests that focusing on colonial violence alone may sideline the root of current pressures. The dedicated investigator's old saying 'follow the money to find the criminal' merits considerable adaptation here: part of the problem is that capitalism's latest neoliberal mutation makes sure that there is no money to spend wisely, so all of us, including state institutions, must make ends meet. Thus, for example, we deal with a paradox both in TW's physical and virtual stagings: on the one hand, the project's experimental education through retrievals of the 'slow pace' of the 'good life' that has come under threat with the advent of the Anthropocene, generates the preconditions for a dialogue between erstwhile centres of colonial power and tropical peripheries. On the other, the institutions/organisations partaking in this dialogue are caught in the cogwheels of capitalism's latest mutation. This mutation demands that TW's current owners generate profit to fund an impoverished urban administration. It also demands to stage spectacles for tourists to enhance the city's global cultural reputation, while simultaneously educating young generations about nature and ecological values. The difficulty in reconciling these is reflected in TW's official (digital) introduction of a Young Brand Ambassador, who enacts 
physical journeys in the region, gets to know TW and its staff, cooperates with local councillors and participates in the organisation of local events and activities (Tropical World, Young Brand Ambassador, 2019).

From the perspective of museological theory, public visitations to museums have always contributed to what is known as 'silent pedagogy,' the provision of non-spoken information by the exhibited objects, followed by 'cues' as to how one can perceive and appreciate particular works (Eisner \& Dobbs, 1988; Usherwood et al., 2005). For young visitors, this is more complicated. Directed play for children has been a major concern among museum theorists, who also advocate the uses of new technologies in the pedagogical communication of museum ideas (Isa, 2017, pp. 80-83). These debates conform to the Western emphasis on goal-oriented play supplanting childhood innocence with adultdetermined developmental achievement, so in museum visits the protection of 'creative play' is framed in rational terms (Nilsson \& Ferholt, 2014). There is a separate, but crucial question to address concerning the ways other world societies treat children: because in non-Western contexts children are regarded as adults from a very early developmental stage, they are left to their own devices to comprehend their environs (Lancy, 2017) - a difference, nevertheless, also applying to the societies of the tropics. I will set this question aside to examine the Young Brand Ambassador initiative in the context of Western pedagogical rationalisation: this young human type emerges on TW's website as a miniature model of the Western adult subject, who organises capitalist mobilities, while slowly side-lining child play from their everyday routines. The Young Ambassador's digital presentation rests on the logos or reason of capitalist economy, branding (Lury, 2004), thus framing the TW's contents as British property.

\section{Heterotropic praxis and capitalism}

We have arrived at the crossroads I discussed the introduction: in it groups of alien non-human but living species, are stripped of their original properties, homogenised as 'tropical collections' and placed between the institutional desire to educate and the pressure to commercialise. The tension is constitutive of the potential fortunes of the entire physical complex in which TW belongs: Roundhay Park. A brief look into this will feed back into our original question regarding heterotropic praxis: an action on representation of other places and cultures in the context of late capitalism and climate crisis. This praxis cannot be excised from debates on how museums experiment within wider design ecologies. It could be argued that experimenting from within capitalist complexities such as the ones outlined here, may unlock new possibilities for reflexive interpretation of Roundhay Park's futures, but this would also merit testing.

A central theme in discourses of climate change/crisis is the reconfiguration of societal habits and economic practices around multiple mobilities (travel, tourism, technology) and 'constructed environments' (Urry, 2007, p. 89; Urry, 2011b, p. 213). Branding human (Young Ambassador) and environmental (Tropical, not 
Brazilian or otherwise nature and climate) groups becomes complicit in the production of a 'TW experience economy,' as an extension of the city's phantasmagoric portfolio. Often, this extension heralds the transformation of educational or activist projects into a 'variation on theme parks' (Sorkin, 1992) - not necessarily the most environmentally sustainable form of action. Indeed, the ways TW's micro-economy and micro-habitual socialisations are currently structured point to precisely such a 'mobility complex,' with all its accompanying risks (Elliott \& Urry, 2010).

This mobility complex displays all the usual contradictions of capitalism (Bell, 1976): on the one hand, it is discursively regulated by modulations of preservation (of living forms) and conservation (of cultures) in the Anthropocenic context, but on the other, it is materially embedded in capitalist practices. Ironically, for example, the Leeds City Council generates revenue by letting designated parts of the Park's areas to external business networks, which organise events such as concerts and festivals. While this secures much-needed revenues, it contributes to the littering of the Park, when organised cleaning services may be insufficient to deal with so much litter. This mission is often undertaken by the 'Friends of Roundhay Park,' a local charity, whose members organise monthly volunteer littering sessions, despite personal health risks, to collect the garbage left behind by insensitive visitors. The charity is not actively involved in the TW's activities, although its council includes Dr Marjorie Ziff, one of the institution's new title namesakes in TW's 2008 relaunching.

Unfortunately, neither the area's beneficiaries nor positive action stemming from the city's administration can hold back the rapid neoliberal restructuring of Leeds' space and culture (Lash \& Urry, 1994). Pragmatically, one may claim that TW's 'cultural enterprise' is operationalised effectively thanks to its geographic proximity to Roundhay Park, a significant leisure node for the city. However, treating the 'Roundhay Park Complex' only in terms of business and capital generation would silence the ways multiple social and cultural realities are embedded in critical conceptions of complexity as more than a property of climate change loops and risks. This complexity entangles three distinct ethico-practical issues: first, Roundhay Park guests' motivations, experiences of nature and culture and on-site performances can be more diverse than those encapsulated by organised conceptions of leisure, tourism or even environmental education (indeed, this may be the reason why no uniform brand/identity has been ascribed institutionally to the complex). Second, the Park itself hosts multiple heritages. By this I refer to both its original landscaping and launching as a working-class leisure ground and the fact that its Arena, which serves as a cricket pitch and a concert ground, overlooks 'Hill 60,' a mount commemorating Leeds' soldiers who died in First World War battles around Hill 60 near Ypres (Friends of Roundhay Park, 2006). Third, the Park snuggles amidst a collection of localities and ethno-cultural groups: historically, Leeds has been a major destination of multiple human migrations, leading to local settlements of different Asian, South American, European and African ethno-cultural groups. Together with Roundhay, these established 
diasporic communities may be affected by unregulated visitor expansion or even excluded from the physical multi-site's use.

Such a historical complexity hosts memories overlaid by lighter forms of consumption, which serve current hospitality needs (Reijnders, 2009). As a result, the multiplicity of the TW's inheritances and histories, are silenced (Jamal, 2019, pp. 175-180). Bringing the bioproperties of TW's collection to an ethically conscious discourse would speak museology's 'third wave' language, allowing for a re-evaluation of the exhibitions' design and practice (Macdonald, 2007; Macdonald \& Basu, 2007), so it considers questions of indigenous justice (Caton, 2013). To stress the plight's cosmopolitan justice, behind generic discussions of 'capitalist contradictions' induced by consumption, lies what museum studies scholars debate as the discursive 'essentialisation' and, ultimately homogenisation of epistemologically distinct 'systems of knowledge and ethical interdictions' (Shelton, 2013, p. 8). In practical terms, this calls for a fusion of British educational curricula on natural science with pedagogical (performative and conceptual) journeys into the lifeworlds and ecosystems from which the TW's collections came, as well as an explicit relational narration of both in the current global environmental crisis. The same phenomenon is considered praxeologically by tourism theorists as a form of 'worldmaking,' a constant making of social environments as liveable, inclusive environments, traditionally assigned to the state but now increasingly capitalist networks (Hollinshead, 2009).

\section{Conclusion}

I performed a reality test on the city council's truth-claiming that through the TW's collections, it provides full proof and disinterested scientific education on the challenges of the Anthropocene. It did that by situating the institution in the wider leisure complex of Roundhay Park and by examining the logic behind the staging of its tropical collections. My experiment on the institutional experiment suggests a number of improvements in its current presentation to visitors. TW is physically connected to a narrative node based on diverse human histories of suffering (from slavery to war), which human actions have now replaced with the prospect of more suffering or even complete human extinction: climate change. However, such reflexive narrating and presenting, can promote global connectivity only under certain conditions. A more collaborative staging in TW's collections could extend to the generation of transnational knowledge networks (e.g., the generation of links between TW and Museu do Amanhã), which take forgotten or subjugated native wisdom seriously in the design of living knowledge, and not artefacts stored in museums so as to venerate inactive inheritances. A collaborative staging of TW's living natural collections can 'untoken' (López et al., 2018) them as bioproperties that belong to someone else.

The possibility to untoken tropical natures-cultures, which can turn the TW into an exemplary fusion of horizons, is implicit in its exhibits, but in relation to its commercial promotion, it is underdeveloped. Their staging as a multisensory form of 
apprehending environmental diversity, which is rooted in multisensory world cultures could challenge the old triptych 'protection - authenticity - learning' that has served as the Western ontological base of modern museums for too long (Chourmouziadi, 2017 , p. 47). Alien nature should be mapped as an alien bioproperty appropriated by Western science. To achieve this in museological terms, the TW may have to consider the adoption of rhizomatic engagement: a clear statement that the cultural/ natural spaces (heterotopias) it currently hosts are places with their own cultural routes and roots, which the whims of colonialism entangled with world centres. It would also involve placing this acknowledgement within a narrative of collective human futures at risk from climate crisis. Enhancing multisensory apprehension in TW's premises would construct a new pedagogy of feeling that focusses on 'empathy rather than simply tolerance toward difference' and consequently 'dialogue and political responsibility' toward shared posthuman futures (Witcomb, 2015, p. 327).

\section{Bibliography}

Aravamudan, S. (1999). Tropicopolitans. Duke University Press.

Azcárate, M. C. (2018). Fueling ecological neglect in a manufactured tourist city: Planning, disaster mapping, and environmental art in Cancun, Mexico. Journal of Sustainable Tourism. 10.1080/09669582.2018.1478839

Augé, M. (2008). Non-places. Verso.

Badmington, N. (2003). Theorizing posthumanism. Culture Critique, 53(1), 10-27.

Bauman, Z. (1996). From pilgrim to tourist: Or a short history of identity. In S. Hall \& P. Du Gay (Eds.), Questions of cultural identity (pp. 18-36). SAGE.

Barthes, R. (1981). Camera lucida, translated by R. Howard. Hill and Wang.

Beck, U. (2009). World at risk. Polity.

Bell, D. (1976). The cultural contradictions of capitalism. Basic Books.

Boltanski, L., \& Thévenot, L. (2006). On justification. Princeton University Press.

Braidotti, R. (2013). The posthuman. Polity Press.

Brockway, L. H. (2002). Science and colonial expansion: The role of the British Royal Botanic Gardens. Yale University Press.

Caton, K. (2013). The risky business of understanding: Philosophical hermeneutics and the knowing subject in worldmaking. Tourism Analysis, 18(3), 341-351.

Chourmouziadi, A. (2017). The deadlock of museum images and multisensoriality. Punctum, 3(1), 45-56.

Cresswell, T. (2010). Towards a politics of mobility. Environment and Planning D, 28(1), 17-31.

Dann, G. M. S., \& Seaton, A. V. (2001). Slavery, contested heritage and thanatourism. In G. M. S. Dann \& A. V. Seaton (Eds.), Slavery, contested heritage and thanatourism. Haworth Hospitality Press.

Danston, L., \& Galison, P. (2007). Objectivity. Zone Books.

Delanty, G. (2009). The cosmopolitan imagination. Cambridge University Press.

Eisner, E. W., \& Dobbs, S. M. (1988). Silent pedagogy: How museums help visitors experience exhibitions. Art Education, 41(4), 6-15.

Elliott, A., \& Urry, J. (2010). Mobile lives. Routledge.

Fletcher, R., \& Neves, K. (2012). Contradictions in tourism: The promise and pitfalls of ecotourism as a manifold capitalist fix. Environment and Society, 3(1), 60-77. 
Foucault, M. (1986). Of other spaces. Diacritics, 16(1), 22-27.

Friends of Roundhay Park. (2006, July). Newsletter. www.forp.co.uk

Gyimóthy, S., Lundberg, C., Lindström, K. N., Hexhagen, M., \& Larson, M. (2015). Popculture tourism: A research manifesto. In D. Chambers \& T. Rakic (Eds.), Tourism research frontiers (pp. 13-26). Emerald.

Haldrup, M., \& Larsen, J. (2003). The family gaze. Tourist Studies, 3(1), 23-46.

Haldrup, M., \& Larsen, J. (2010). Tourism, performance and the everyday. Routledge.

Herzfeld, M. (2002). The absent presence: Discourses of crypto-colonialism. South Atlantic Quarterly, 101(4), 899-926.

Hollinshead, K. (2009). The 'worldmaking' prodigy of tourism: The reach and power of tourism in the dynamics of change and transformation. Tourism Analysis, 14(1), 139-152.

Ingold, T. (2011). The perception of the environment (2nd ed.). Routledge.

Isa, B. (2017). Museum pedagogy and learning experiences [Unpublished PhD thesis, School of Education, College of Design and Social Context, RMIT].

Jamal, T. (2019). Justice and ethics in tourism. Routledge/Earthscan.

Jasanoff, S., Markle, G., Petersen, J., \& Pinch, T. (1995). Handbook of science and technology studies. SAGE.

Lancy, D. (2017). Raising children. Cambridge University Press.

Larsen, J. (2005). Families seen photographing: The performativity of tourist photography. Space and Culture, 8(4), 416-434.

Larsen, J., Urry, J., \& Axhausen, K. W. (2006). Networks and tourism: Mobile social life. Annals of Tourism Research, 34(1), 244-462.

Lash, S., \& Urry, J. (1994). Economies of signs and space. SAGE.

Latour, B. (1987). Science in action. Oxford University Press.

López, M., Lugo, A., \& Vargas, O. (2018). Counternarratives of community-based advocacy as sources of knowledge for urban planning. eJournal of Public Affairs, 7(2). http://www. ejournalofpublicaffairs.org/wp-content/uploads/2018/08/206-1354-1-GalleyRevision.pdf

Lury, C. (2004). Brands. Routledge.

MacCannell, D. (2011). The ethics of sightseeing. University of California Press.

Macdonald, S. (2007). Interconnecting: Museum visiting and exhibition design. CoDesign, 3, 149-162.

Macdonald, S., \& Basu, P. (2007). Exhibition experiments. Blackwell.

MacKenzie, J. M. (1997). Empires of nature and the nature of empires. Tuckwell Press.

Merson, J., (2000). Bio-prospecting or bio-piracy: Intellectual property rights and biodiversity in a colonial and postcolonial context. Osiris, 15, 282-296.

Moore, J. W. (2016). Anthropocene or capitalocene? PM Press.

Nilsson, M., \& Ferholt, B. (2014). Vygotsky's theories of play, imagination and creativity in current practice: Gunilla Lindqvist's 'creative pedagogy of play' in U.S. kindergartens and Swedish Reggio-Emilia inspired preschools. brPERSPECTIVA, Florianópolis, 32(3), 919-950.

Noblet-Ducoudré, N., Prinn, R., Reynolds, J. F., \& Salas, J. D. (2004). Nonlinearities, feedbacks and critical thresholds within the earth's climate system. Climate Change, 65(1-2), 11-38.

Rauch, A. (2018). Concerning astonishing atmospheres. Mimesis International.

Reijnders, S. (2009). Watching the detectives. Inside the guilty landscapes of Inspector Morse, Baantjer and Wallander. European Journal of Communication, 24(2), 165-181.

Sahr, W. D. (2011). The urban staging of politics: Life worlds, aesthetics, and planning and an example from Brazil. In H. Schmid, W.-D. Sahr, \& J. Urry (Eds.), Cities and fascination (pp. 107-128). Routledge. 
Salazar, N. B. (2012). Tourism imaginaries: A conceptual approach. Annals of Tourism Research, 39(2), 863-882.

Salazar, N. B., \& Graburn, N. H. H. (2016). Towards an anthropology of tourism imaginaries. In N. B. Salazar \& N. H. H. Graburn (Eds.), Tourism imaginaries (pp. 1-30). Berghahn.

Shelton, A. (2013). Critical museology: A manifesto. Museum Worlds: Advances in Research, $1(1), 7-23$.

Soper, K. (2007). Re-thinking the 'good life': The citizenship dimension of consumer disaffection with consumerism. Journal of Consumer Culture, 7(2), 205-229.

Sorkin, M. (1992). Variations on a theme park. Noonday.

Sorkin, M. (2008). Back to zero: Mourning in America. In M. Sorkin (Ed.), Indefensible space (pp. 213-232). Routledge.

Taussig, M. (1997). The magic of the state. Routledge.

Tropical World, Virtual Tour. (2019). Australasia House. https://www.roundhaypark.org. uk/tropical-world-leeds/tropical-world-tour/Australasia-House.html

Tropical World, Young Brand Ambassador. (2019). Read all about Thomas's experience as Tropical Worlds first young brand ambassador with his regular updates. https:// tropicalworld.leeds.gov.uk/tropical-world-brand-ambassador-competition

Tzanelli, R. (2018a). Cinematic tourist mobilities and the plight of development. Routledge.

Tzanelli, R. (2018b). The 'mangle' of human practice: Museu do Amanhã's artistic staging as a socio-scientific narrative on climate change. Transfers, 18(2), 138-141.

Urry, J. (2005). The complexity turn. Theory, Culture \& Society, 22(5), 1-14.

Urry, J. (2007). Mobilities. Polity.

Urry, J. (2011a). Climate change and society. Polity.

Urry, J. (2011b). Excess, fascination and climates. In H. Schmid, W.-D. Sahr, \& J. Urry (Eds.), Cities and fascination (pp. 209-224). Routledge.

Urry, J., \& Larsen, J. (2011). The tourist gaze 3.0. SAGE.

Usherwood, B., Wilson, K., \& Bryson, J. (2005). Relevant repositories of public knowledge? Libraries, museums and archives in 'the information age'. Journal of Librarianship and Information Science, 37(2), 89-98.

Witcomb, A. (2015). Toward a pedagogy of feeling: Understanding how museums create a space for cross-cultural encounters. In A. Witcomb \& K. Message (Eds.), The international handbooks of museum studies (pp. 321-344). Wiley. 